\title{
Um discurso da Belle Époque: moda e modo de vida na revista Illustração Pelotense
}

Ana Claudia de Oliveira

Fabiane Villela Marroni

Resumo: Este artigo tem como objetivo a análise da revista Illustração Pelotense, que circulou na cidade de Pelotas, localizada no extremo sul do Rio Grande do Sul, no início do século XX, período compreendido como sua Belle Époque. Tendo como base teórica e metodológica a semiótica discursiva, pretende-se recuperar os valores e o modo de vida da sociedade pelotense dessa época, a partir das capas, dos anúncios e das crônicas veiculadas por essa revista. Por ser um objeto que articula diferentes linguagens, buscou-se, também, como aporte teórico, correntes vinculadas à semiótica discursiva, como a do visual e a das mudanças. Dos desejos individuais à consagração pública, a assimilação de outros valores é incorporada à cidade e mostrada através da mídia impressa.

Palavras-chave: semiótica discursiva; Illustração Pelotense; modo de vida.

Abstract: A discourse on Belle Époque: fashion and lifestyle in the magazine Illustração Pelotense This article analyzes the magazine Illustração Pelotense, which circulated in the city of Pelotas, Rio Grande do Sul, in the beginning of the 20th century, a span known as its Belle Époque. It intends to bring back the values and the lifestyle of the Pelotas' society, depicted in the covers, adverts and chronicles conveyed by the magazine, based on the theoretical and methodological aspects of the discursive semiotics. Since its object articulates different languages, this text also seeks as theoretical support some trends linked to discursive semiotics, such as the visual and the changing ones. From the personal desires to the public consecration, the absorption of other values is embedded in the city and displayed through the press.

Keywords: discursive semiotics; magazine Illustração Pelotense; way of life.

No século XIX, a cidade de Pelotas, situada no extremo sul do Brasil, no estado do Rio Grande do Sul, caracterizava-se como um centro de expansão rural e econômico. O seu rápido desenvolvimento não se deu por acaso, mas resultou de uma combinação 
de fatores sociais e de condições geográficas, especialmente no que se refere a sua localização às margens do Canal São Gonçalo, da Lagoa dos Patos, e de inúmeros arroios que cortam suas terras. Entre o final do século xıx e o início do século xx, vivia seu apogeu cultural, caracterizando uma cidade que ainda se beneficiava com a riqueza gerada no ciclo do charque. No auge da indústria saladeril, todo o dinheiro acumulado nos períodos de safra passou a ser gasto nos centros mais desenvolvidos de então. Na época, os descendentes de charqueadores costumavam deslocar-se para as grandes capitais do centro do país, como Rio de Janeiro e São Paulo, ou para a Europa, principalmente Portugal e França, com o propósito de completar e aprimorar seus estudos em diferentes áreas do conhecimento. As frequentes viagens desses jovens e de suas famílias ao exterior e, em decorrência, as inúmeras visitas de estrangeiros à cidade fizeram com que outros valores, principalmente europeus, se agregassem à cultura local, o que, aos poucos, foi dando forma e estilo a essa cidade. Ainda que o declínio do ciclo de ouro das charqueadas tenha começado no final do século xIx, em meados do século xx, a chamada alta sociedade ainda colhia seus frutos e ostentava riqueza à custa de seus ganhos. Em seu livro Opulência e Cultura, Magalhães (1993, p. 134) faz referências ao modo de vida pelotense dessa época:

Na verdade, pode-se afirmar, com plena convicção, que os hábitos gauchescos entre eles, por exemplo, o de tomar chimarrão e o de vestir-se a caráter, bastante comuns nas cidades da Campanha - não chegaram a influir sobre o cotidiano dos pelotenses durante todo o século xıx. Em Pelotas, os costumes europeus é que foram sempre dominantes no comportamento coletivo.

Conforme esse mesmo autor, na segunda metade do século XIX, "[...] muito se escreveu, muito se declamou, muito se discursou", acrescentando que, "na imprensa e no livro - seja por uma preferência sociológica, seja pela maior facilidade de veiculação -, a produção local proliferou muito mais do que em outros setores, como, por exemplo, na música e nas artes plásticas" (ibidem, p. 275-276). Fato que se observa, também, nas primeiras décadas do século xx, em função do poder de divulgação das grandes livrarias e editoras da cidade, particularmente da imprensa jornalística e publicitária.

Em razão de Pelotas ter-se tornado uma cidade com considerável efervescência cultural, localizada no extremo sul do Brasil e, na ocasião, diferenciada das demais cidades gaúchas pelas suas características anteriormente referidas, é que se propõe, neste trabalho, analisar os valores e o modo de vida da sociedade pelotense através da sua mídia impressa, mais especificamente a partir da revista Illustração Pelotense. Ideais de progresso divulgados pela imprensa e ancorados num período determinado, conhecido como Belle Époque - aqui delimitado, para a cidade de Pelotas, entre os anos de 1890 e 1927. Uma visão de mundo que se enunciava com marcas de um outro, em um período eufórico, num discurso de modernidade, de significativas transformações no modo de vida da cidade. A Belle Époque caracterizou-se como um período de mudanças sociais, 
políticas, culturais, tendo sua origem na França, no final do século xIx, ainda iluminada pelos ideais da Revolução Francesa e pela Revolução Industrial. Um percurso em busca da civilidade, num discurso de modernidade, muito em função das novas tecnologias que surgiram na época.

A revista Illustração Pelotense manteve-se em intensa atividade entre os anos de 1919 e 1925. A escolha por essa mídia impressa como objeto de análise deve-se à expressiva circulação de suas edições, que se constituíam em publicações preferenciais de grande número de leitores, suscetíveis às matérias e aos anúncios divulgados em suas páginas. Por meio de seus formatos, de suas ilustrações e de seus conteúdos, essa revista revela o modo de vida da sociedade local em relação ao consumo, aos gostos, aos hábitos e às preferências. Esses aspectos serão revistos por meio da análise de reclames, fotografias, notas e notícias veiculados por esse periódico e considerados no decorrer do trabalho.

A Illustração Pelotense foi uma das primeiras revistas de variedades a circular na cidade de Pelotas no início do século passado e uma das primeiras do município a utilizar a fotografia em suas edições. Ela mostrava os acontecimentos sociais, as novidades locais e de outros municípios da região; publicava crônicas, poemas e muitos anúncios, divulgando as potencialidades regionais de moda e literatura ou as inovações decorrentes do avanço científico e tecnológico.

Passado o século xıx, em Pelotas, a visão eufórica da modernidade ainda maravilhava sujeitos que ansiavam por sua inserção num novo tempo, em uma dada realidade, e a revista, como mídia impressa, era um meio, uma forma de dar visibilidade às transformações do cotidiano. A valorização do novo, do que estava por vir, do sentimento de modernidade, do progresso, enfim, de civilidade, retratava o período da Belle Époque. Ao falar do novo, Ciaco (2012, p. 336) afirma que "é fundamental ter-se claro que este estatuto do novo não estabelece posições estanques, fixas, bastando serem identificadas em determinada grade de leitura para ter sentido". Os grandes centros ou as cidades menores, que de alguma forma produziam riqueza (como foi o caso de Pelotas, em função da indústria saladeril), observavam as vertiginosas mudanças no velho mundo e tentavam reproduzi-las. Os mais abastados não poupavam esforços para seguir, à risca, as tendências inovadoras, principalmente em relação ao bem-estar social.

No período da Belle Époque, a palavra era civilização: a moda, o progresso. Ao falar de moda e política, Landowski (2002, p. 96) observa:

[...] seguir uma moda, isto é, adotar as marcas com o auxílio das quais determinado meio declina figurativamente sua identidade, é, no mínimo, sugerir que se pertence à classe social em questão, e com isso indicar que se assume a pertença a ela, se for o caso, ou demonstrar que se gostaria, pelo menos, de passar por alguém que "é dela". Desse ponto de vista, as formas que a moda (como fenômeno geral) articula diferencialmente (diversificando-se na proporção da variedade dos segmentos do público que ela toca) agem, pelo menos em 
teoria, tanto como máscaras, quanto como reveladores: se elas servem o mais das vezes para dizer as identidades, elas podem, por outro lado, se transformar a cada instante em meios de as travestir ou de as dissimular.

A maioria da população da cidade de Pelotas não tinha acesso, nem desfrutava do conforto, do luxo, das festas e das benfeitorias proporcionados pelo progresso da cidade. A elite era a grande fomentadora desse novo modo de vida. O querer-viver e estar e o quererser-visto como uma sociedade civilizada eram questão de honra para essa classe, que assimilava os valores importados dos lugares mais evoluídos, declinando de seus traços originais.

Considerando as transformações ocorridas nessa época como moda, e seguindo os postulados de Landowski (ibidem) sobre a semiótica da mudança, concorda-se que o que interessa são os chamados sujeitos nas suas relações com o mundo-objeto, como nas relações intersubjetivas que eles mantêm. São entidades que vivem as mudanças que as afetam, que procuram dar um sentido ao que acontece. "Nós 'existimos', sem dúvida, mas, sobretudo, nós nos vemos existir, viver, mudar: é dessa reflexividade que é preciso partir (e é de seus efeitos que é preciso dar conta), a partir do momento, em todo o caso, em que o que se visa construir é uma semiótica da mudança" (ibidem, p.103). Ainda de acordo com o mesmo autor:

Para que a mudança, quer se produza fora, no espaço natural ou cultural circundante, ou no próprio interior de si, possa ser apreendida e vivida como algo que faz sentido, é preciso, portanto, postular, entre os que a provocam ou a sofrem, a capacidade de se apreender a si mesmos, reflexivamente, em cada um dos dois planos que acabamos de distinguir: ao mesmo tempo como seres que, em profundidade, seja o que for que aconteça, continuarão a ser eles mesmos em sua "identidade" primeira, e ao mesmo tempo, contudo, na superfície, como seres indefinidamente em vias de se tornarem outros (ibidem).

A Belle Époque pelotense assinala uma rápida incorporação de elementos novos a uma cidade que teve suas raízes na atividade rural. No decorrer dos anos oitocentos, ela se transformou, moldando-se aos estilos que eram absorvidos no Brasil. Esses estilos contribuíram para uma adaptação e recriação dos moldes europeus, de certa forma, "abrasileirados" (SANTOS, 2002). O tema central da cultura da elite brasileira na Belle Époque baseava-se entre recusa e evasão, pois, nas mudanças que ocorreram nesse período, a elite celebrava o que era feito e, também, o que era desfeito. Negava sua própria essência, dissociando-se de valores agora vistos como ultrapassados (NEEDELL, 1993).

Para bem explicar essas mudanças, comecemos pela análise da página de número 12, do dia 16 de dezembro de 1924 (fig.1), da revista Illustração Pelotense. Nela, há um desenho, no plano superior da folha, que ilustra a mulher de hoje. Informada, ela lê jornais e/ou revistas em vários momentos e situações: na cama, tomando chá ou, até, na banheira. A legenda explica em letras maiúsculas: "ELLAS... DE HOJE". Abaixo, em plano inferior, há um texto, a seguir transcrito: 
Não ha modas novas; não ha senão modas renovadas. Um grande jornal parisiense nota que voltou a moda dos brincos nas orelhas em consequencia da mudança que vai haver nos penteados. Diz elle.

As mulheres - finalmente! - vão renunciar a occultar as orelhas debaixo de mecha de cabellos.

Os cabellos levantam-se e a orelha vai se usar, de novo, ornada de brincos e outras joias. Brincos com pingentes, argola em esmalte preto incrustado de pedras finas, com pingentes alongados. E a joia fica tão bem que a gente pergunta a si propria como a moda poude dispensar até hoje. Mas a orelha já não é furada. Essa barbaridade passou. O brinco é suspenso por uma tarracha. E para adoptarem esse adorno de nossos avós, para andarem á moda, para serem bellas, nossas elegantes não terão sequer que soffrer. (ILLUSTRAÇÃO..., 1924, p.12)

No mesmo plano inferior, à direita, em destaque, diferenciando-se pelo tipo gráfico utilizado e em tamanho maior que o do corpo do texto, um anúncio: "Bella Cutis! Creme S. S. White para o rosto". Voltando ao plano superior, ao lado do desenho, portanto ao lado direito da página, uma coluna com o poema chamado Lyrismo, dedicado à Walquyria por Jorge Sallis Goulart. Outro, logo abaixo desse, chamado Paganismo, escrito por Walquyria Neves Goulart. No plano inferior da página, há uma notícia sobre as inglesas e suas formas: "As inglezas de agora são uma ou duas pollegadas mais altas e têem duas ou tres pollegadas mais de largura de peito do que suas avós. Em consequencia, estão se tornando cada dia menos femininas de aspecto" (ibidem).

Apreendendo a página como um todo, há uma mulher moderna, que se informa e mantém-se em constante sintonia com a moda, com o que há de novo. Mulher englobada por um lirismo, manifestado pela expressão viva de sentimentos. $\mathrm{O}$ simulacro da mulher moderna, atenta às mudanças do seu tempo. No conjunto da página, a afirmação da liberdade, valorizada euforicamente, da mulher de hoje, evidencia-se pelo caráter independente e inovador de suas escolhas vestimentares. Mas, para estar na moda, para ser independente, era preciso, paradoxalmente, conformar-se com os valores vindos do outro. De fato, o que significava estar na moda, em primeiro lugar, era desvincular-se de valores e modos de vida considerados atrasados. O mais atrasado consiste, desta forma, em manter-se afastado, precisamente, da informação sobre o que se (quer dizer, o outro) considera atrasado ou, no oposto, da moda atual. O raciocínio publicitário, já na Belle Époque, fechava-se num círculo sem fim. 


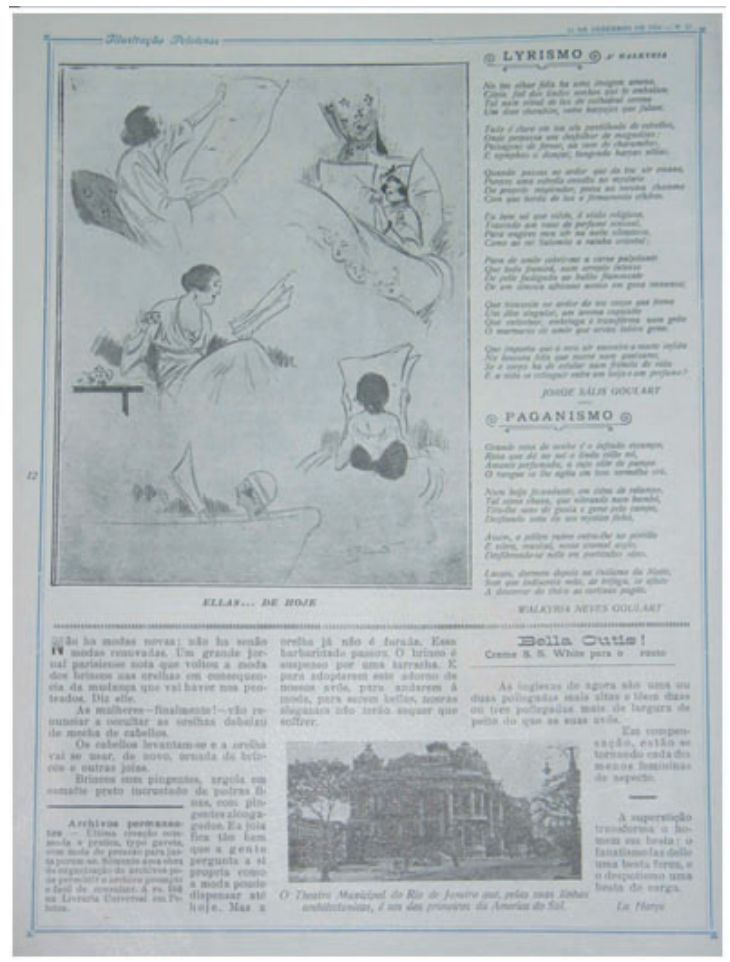

Fig. 1. Página 12 da revista do dia 16 de dezembro de 1924, ano VI, n. 21. Destaque para a ilustração do alto da página: a mulher da atualidade e seu novo modo de ser - em qualquer momento e em qualquer situação, o importante era manter-se sempre bem informada.

Como nas revistas femininas de hoje, mas com mais variações no estilo gráfico, as mulheres sempre foram o tema de capa preferencial da revista Illustração Pelotense (fig. 2 e 3). Buiton (2014, p. 42-43) diz que, assim como em tempos passados, atualmente:

[...] o discurso da imprensa feminina é fundamentalmente de sugestões normativas, de receituário para todo tipo de ação humana. Em termos linguísticos, o uso da função conativa - lembremos Jakobson - com seus imperativos e vocativos, transforma as frases em chamamentos ou ordens, induzindo à aceitação e quase nunca à contestação. Assim, "corra", "emagreça", "tenha prazer", "fique bonita", "viaje", "medite" estão nas capas e páginas das revistas femininas no planeta inteiro... O jeito amistoso afasta o questionamento e até a simples dúvida. A função conativa é também a função preferencial do discurso publicitário. O circuito se fecha: a sugestão da matéria de beleza, saúde ou moda é feita no mesmo tom que os anúncios de todas as mídias. 


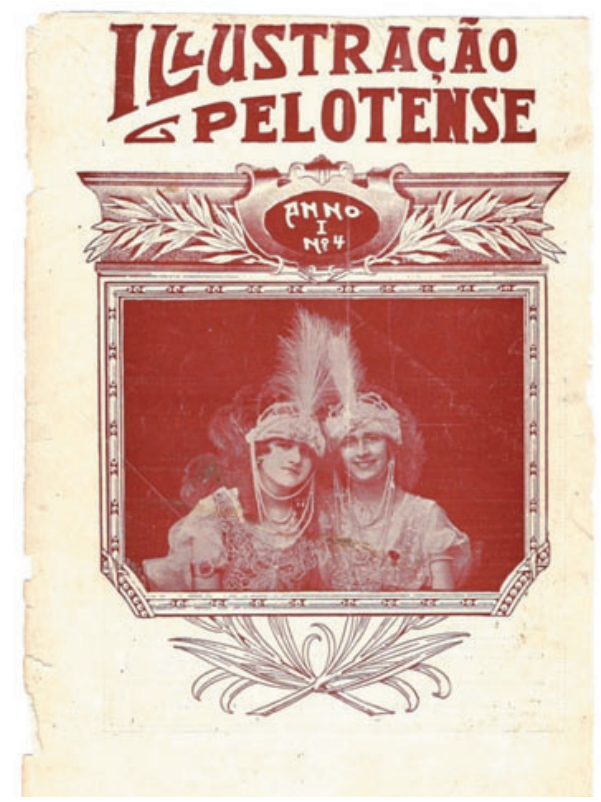

Fig. 2. Capa da revista do dia $1^{\circ}$ de setembro de 1919, ano l, n. 4. As mulheres são destacadas, ao centro, por uma moldura. As capas da revista Illustração Pelotense não mantinham uma identidade visual. A cada número, uma configuração gráfica.

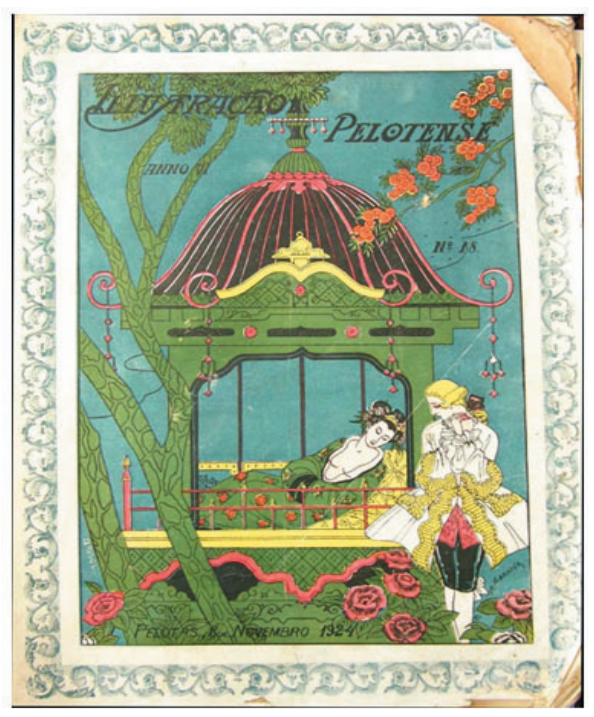

Fig. 3. Capa da revista do dia $1^{\circ}$ de novembro de 1924, ano VI, n. 18. No todo da página, campos estilísticos variados. A mulher, oriental, tem ao lado um homem com vestimenta aristocrática. De um lado, as formas orgânicas e, de outro, a inspiração de pinturas japonesas, típicas da Belle Époque. 
Em vários momentos da revista, e em todo o seu período de circulação, desenhos de figurinos de mulheres podem ser visualizados, com a finalidade de divulgar as diversas casas de moda da cidade. Sob a temática do luxo, figurativizavam tendências da moda. Na imagem seguinte (fig.4), o simulacro da mulher em ascensão, do espaço privado do ambiente familiar ao espaço público através da moda. Em estado de contemplação, ela está ao centro, emoldurada como num quadro, para ser vista e admirada. A afirmação da liberdade vem na forma de se tornar visível um processo de mudança, o seu novo modo de ser, para tentar distanciar-se do papel de mulher ornamento. Com o pé e a parte mais abaixo do vestido saindo da moldura, a mulher parece em vias de emancipar-se do quadro constrangedor figurativizado pelas pesadas linhas horizontais e verticais que parecem ainda a aprisionar. Como em um processo de libertação, de mudança, ela parece querer romper com as vozes da opressão, manifestadas pela cultura de então, para avultar sua incorporação na vida social e/ou econômica.

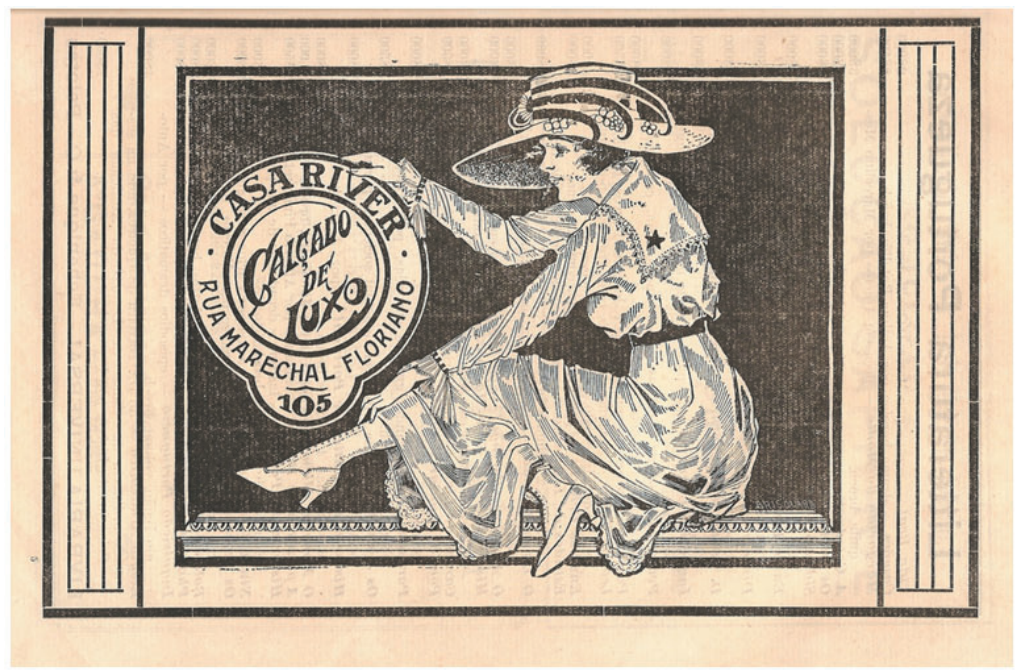

Fig. 4. Propaganda veiculada na Illustração Pelotense, ano III, n. 12, 16 de junho de 1921.

O tema da beleza, figurativizado através dos conselhos sobre cuidados com a pele, com os cabelos, com a saúde de uma forma geral, é uma constante. Era feio ser feia, conforme o anúncio da Farinha Pollah (fig.5). Ser bonita fazia parte da competência da mulher - uma forma concreta do poder. No anúncio dessa farinha, colocado logo a seguir, observa-se uma manipulação por intimidação, em que o destinador faz um juízo negativo das mulheres, suas destinatárias que continuam feias, levando-as a um dever-fazer - "Se você não usar Pollah, ficará feia!" (ILUSTRAÇÃO..., 1921). No entanto, 
esta manipulação é encoberta por uma sedução no momento em que, com a farinha Pollah, todas se tornarão belas.

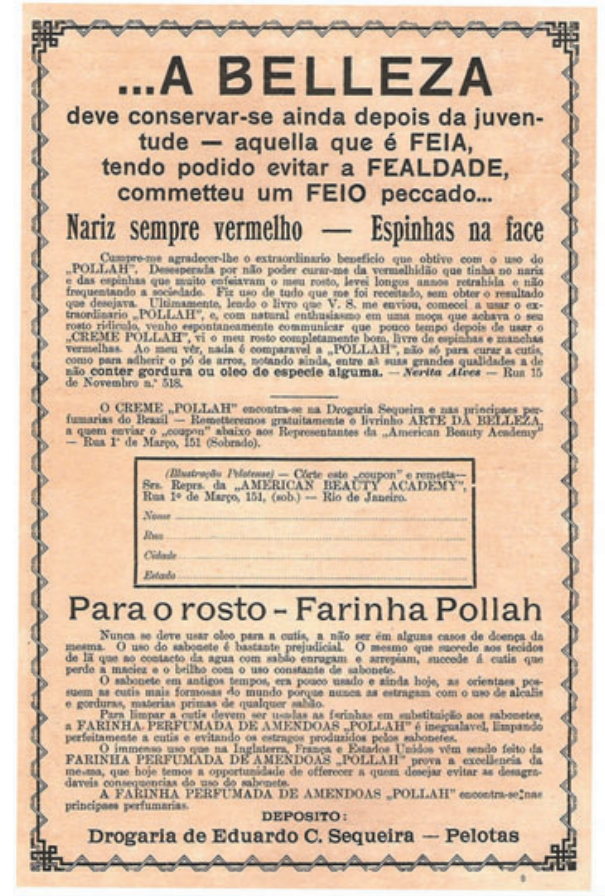

Fig. 5. A beleza através da Farinha Pollah. Os anúncios da farinha eram encontrados, praticamente, em todas as edições da revista. (Fonte: Illustração Pelotense, ano III, n. 12, 16 de junho de 1921).

A Illustração Pelotense caracterizava-se como uma revista que ditava comportamentos e assumia valores relacionados ao modo de vida do cotidiano. Lançada no ano de 1919, permaneceu em atividade por volta de sete anos. Possuía, em média, 24 páginas, com impressão feita nas oficinas de Echenique e Comp., também de seus proprietários. Era uma edição quinzenal, com 24 fascículos por ano e com uma tiragem de 1000 exemplares a cada número. Passou por duas fases: na primeira, compreendida entre os anos de 1919 a 1923, teve como redator Coelho da Costa e diretor artístico Luiz Lanzetta; na segunda fase, entre os anos de 1924 e 1925, foram seus diretores Coelho da Costa e Aristides Bittencourt. Em qualquer número dessa revista quinzenal, podem ser encontradas notícias sobre bodas ou viagens, conclusão de cursos de capacitação superior ou técnica, literatura, vida social, esportes ou entretenimento, além dos reclames de toda a ordem.

Ao analisar a capa de seu primeiro número (fig.6), pode-se observar uma oposição entre claro e escuro. Na área clara, ao centro da página, vê-se a imagem de um rosto, 
um perfil de mulher que olha para fora. No plano superior, a marca da revista se mostra através de uma fonte estilo art-nouveau, serifada e com traços densos. No plano inferior, o ano e o número da edição. O restante da página é escuro, num verde em tonalidade forte, que contrasta com as áreas claras. A mulher, retratada de perfil, tem o olhar fixo, um olhar para fora, para longe, distante, como quem fixa a atenção sobre o outro - o diferente, o novo, o almejado. É nela que o olhar do leitor se concentra. No restante da página não há nada, a não ser um escuro disforizante, uma ausência que se opõe à presença, por si só, da mulher. Nesta estruturação, é como se o enunciador dissesse: a Illustração Pelotense é você, estabelecendo um simulacro do seu próprio leitor.

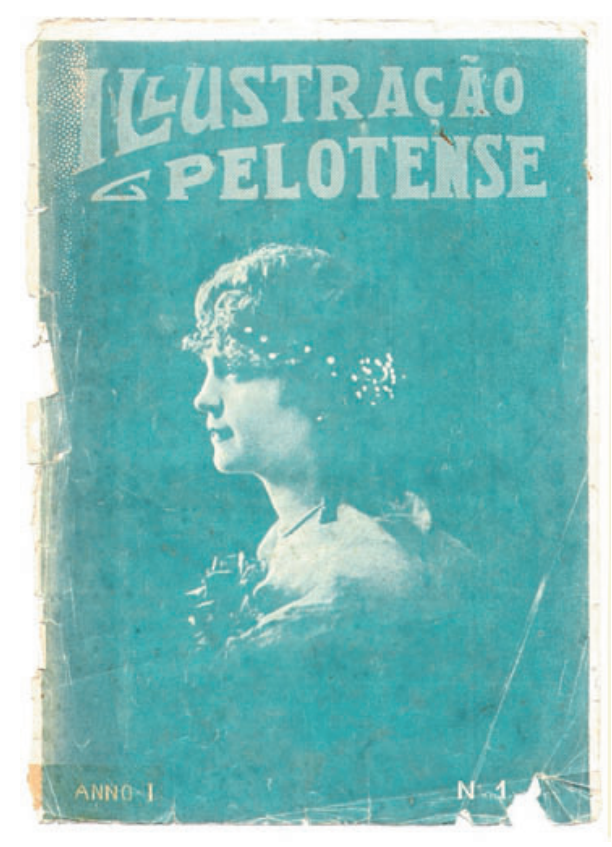

Fig. 6. Capa da edição ano I, n. 1, da revista Ilustração Pelotense, 1919.

Nessa estratégia, há um lugar demarcado para o enunciatário (destinatário-leitor), construído pelo enunciador. Pela convocação visual, por um entrelaçamento de formantes, é gerado um efeito de proximidade, de convocação do enunciatário.

O exemplar da primeira edição da Illustração Pelotense, a que se teve acesso, não estava completo. Apesar da falta de algumas páginas, é possível apreender algumas informações nela estampadas. Nas páginas iniciais, anúncios variados: bancos da Província, Nacional do Commercio, Banco Commercial Franco-Brazileiro; casas de moda, como A Triumphante, Au Petit Paris, Casa Americana; anúncios de livros, como O espírito 
das armas brasileiras: nossas guerras, de Fernando Luis Osorio (filho); de remédios, como Luesol, Galenogal; além de uma cervejaria Sul Rio-Grandense, dentre outros. Nas últimas páginas da revista, mais reclames: motores para instalação elétrica na campanha Delco Light; Grande Fábrica de roupas, movida à eletricidade; joias, relógios e artigos de metal e bronze, encontrados na loja Dreyfus \& Gomes; confeitarias, como A Dalila, que recebia especialidades diretamente dos principais mercados nacionais e estrangeiros; fábrica de móveis Arthur Quintas - fábrica de móveis de luxo e de todos os estilos, fábrica de malas, além de anúncios de bancos, como os do Banco do Brasil, do Banco Pelotense e do Bank \& Brazilian Bank, Limited., com sede em Londres. Na contracapa, a propaganda de uma casa de pompas fúnebres Moreira Lopes, que, em seu anúncio, coloca: "irrefutavelmente mantém o maior e o mais completo sortimento de coroas para túmulos" (ILLUSTRAÇÃO..., 1919).

Ao se fazer a análise da capa e contracapa (fig.7), observa-se, em um nível fundamental, uma oposição semântica de base vida vs morte. Na capa, a luz ilumina a jovem, numa afirmação da vida e numa negação da morte; na contracapa, o anúncio de um fim, um percurso encerrado, a evocação da morte com o reclame de pompas fúnebres, uma ausência. No espaço, na topologia das páginas, a instalação de um tempo. Entre o início do percurso e seu fim, os acontecimentos. Assim como a vida, é a revista. Da efemeridade, do passageiro, do transitório, afirma-se uma presença, o cotidiano em revista, em cada número de sua publicação.
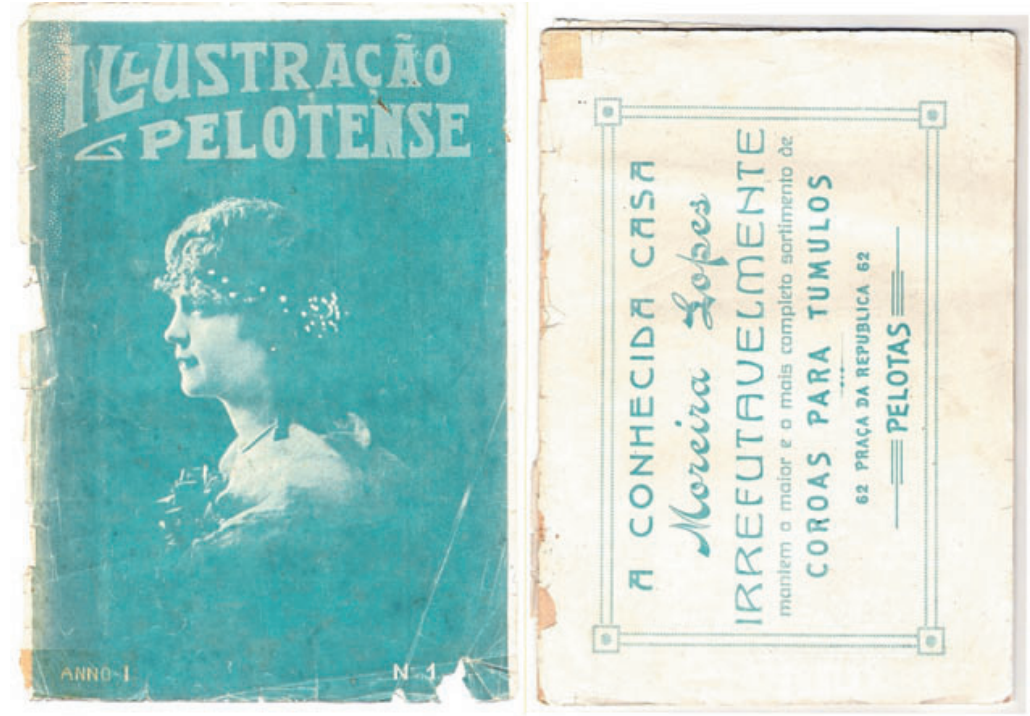

Fig. 7. Capa e contracapa da edição número 1 da revista Illustração Pelotense, 1919.

Nas páginas centrais da revista, parte englobada pelos anúncios, fotografias que retratam o modo de vida dessa época. Nelas, podem ser vistos acampamentos de grupos 
de atiradores, exéquias do presidente Sidonio Paes, as mademoiselles Maria Mourgues e Idemora Oliveira, além do prédio do Banco Nacional do Commercio. Na página de número três (fig.8), a oposição entre vida e morte é reiterada. No plano superior, a foto com as exéquias do presidente português Sidonio Paes, mandadas celebrar pelo Congresso Português em $1^{\circ}$ de dezembro. Na imagem, um grupo de homens, alinhados em frente à Catedral São Francisco de Paula, em Pelotas. No plano inferior, a foto de uma menina e de mademoiselles. Sob o título Missa na Cathedral, era como se essa página figurativizasse o percurso natural - mais uma vez destacado - entre a vida e a morte. Do nascimento, passando pela juventude, até o final, a morte, a ausência de uma presença.

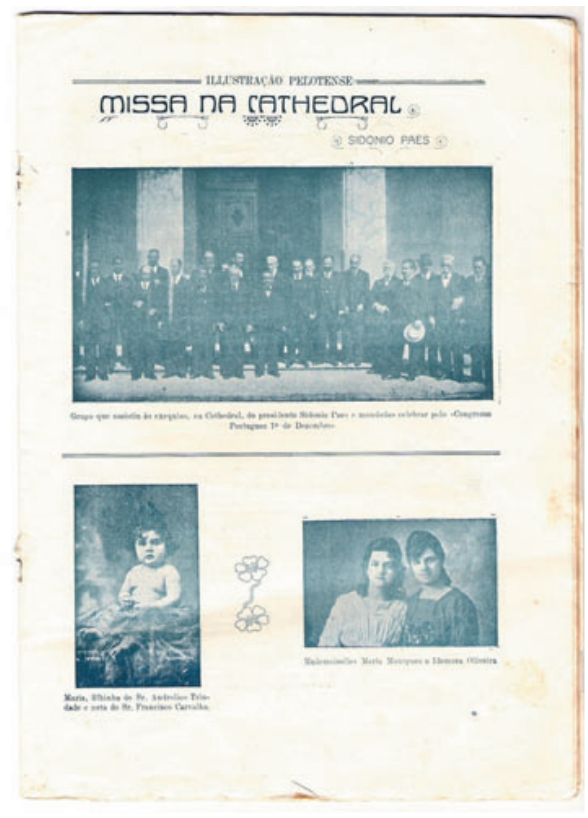

Fig. 8. Página interna da revista Illustração Pelotense, 1919, p. 3.

Retornando à fotografia estampada na página, com título Missa da Cathedral (fig.8), vê-se que é possível considerá-la como um retrato oficial. Em seu artigo Flagrantes delitos e retratos, Landowski (2004) refere-se aos regimes de encenação do corpo na imprensa, a partir de retratos de políticos.

O retrato oficial não visa, essencialmente, a permitir o reconhecimento de um dado indivíduo nem a penetrar em certas facetas que, captadas no instante, seriam mais reveladoras do que outras. Em vez disso, empenha-se em fixar para a posteridade uma imagem que seja ponto a ponto conforme a uma norma 
sócio-estética de representação pré-definida. Consequentemente, não nos diz quase nada da pessoa que nos mostra, a não ser que ela ocupa dignamente a posição social que a vemos ocupar. Ele consagra, assim, o estatuto do sujeito, ignorando deliberadamente o seu eu. De fato, longe de procurar revelar o que poderia se esconder aquém ou além do parecer, ele se limita a mostrar que o sujeito parece mesmo com seu papel social (ibidem, p.46).

Era comum encontrar retratos oficiais na Illustração Pelotense. Ao se trabalhar no âmbito dessa revista, é possível identificar, fazendo uso das palavras de Landowski (ibidem), os "papéis sociais" de ilustres personalidades, "consagrando o estatuto do sujeito e ignorando o seu eu". A postura, o modo de vestir e o espaço que ocupam na página, refletem, nitidamente, seus papéis sociais, que se consolidam como uma imagem para a posteridade.

Segundo Gontijo (2001, p. 198), no final do século xix e início do século xx:

[...] a maioria dos fotógrafos estabelecidos no Brasil focou seu negócio nos retratos. Havia uma demanda crescente de eternizar-se através dos carte de visite, retratos produzidos em estúdios com cenários e adereços. Se deixar fotografar por um fotógrafo de renome passou a ser símbolo de valor social.

Algumas fotografias divulgadas na Illustração Pelotense eram produzidas num estilo conhecido como carte de visite, ou seja, os retratos individuais ou grupais eram tirados por renomados fotógrafos, que orientavam, também, as poses dos integrantes da foto em frente a cenários fixos em seus ateliers. Nas imagens das revistas publicadas nos dias 16 de janeiro de 1921 e $1^{\circ}$ de novembro do mesmo ano (fig. 9 e 10), é possível observar grupos de pessoas ou famílias que se reuniam para registrar momentos especiais por meio da fotografia.

As imagens fotográficas em estilo carte de visite constituíam-se, nessa época, em um objeto de desejo e, caso fossem veiculadas pela mídia impressa, tornavam-se objeto de poder. As festas e os enlaces matrimoniais, frequentemente, eram divulgados por essa revista. Seguindo a moda, a Illustração Pelotense adotava o mesmo padrão. Ela retratava o cotidiano não só da elite pelotense, como, também, o de outras localidades do Rio Grande do Sul.

Ao se observar a fotografia exposta a seguir, nota-se que o cenário compõe-se de coqueiros, figurativizando um clima tropical. As mulheres (fig.9), em primeiro plano, usam vestidos com decotes em estilo bateau e chapéus avantajados. Um estilo de vestir segundo as normas ditadas na Europa, que contrasta com o cenário nitidamente tropical. A cena caracteriza bem a assimilação e incorporação de traços que não são seus. Esse devir figurativiza, aqui, uma mudança, uma transformação. Prosseguindo na análise da fotografia, vê-se a manutenção dos grandes chapéus, adotados no período da Belle Époque, e a assimilação de modelos lançados já no início do século xx, como os vestidos com gola canoa. O desenvolvimento de diferentes tecnologias possibilitava que essas 
novidades fossem rapidamente incorporadas ao modo de ser das mulheres da sociedade, num processo de constante reconstrução. A moda adotada pelo grupo, o modo de posar para o retratista, o palco do espetáculo, figurativizado pelo cenário da fotografia, são reiterados pela legenda: "Um grupo de distinctas senhorinhas da melhor sociedade pelotense" (ILLUSTRAÇÃO..., 1921, p.2).

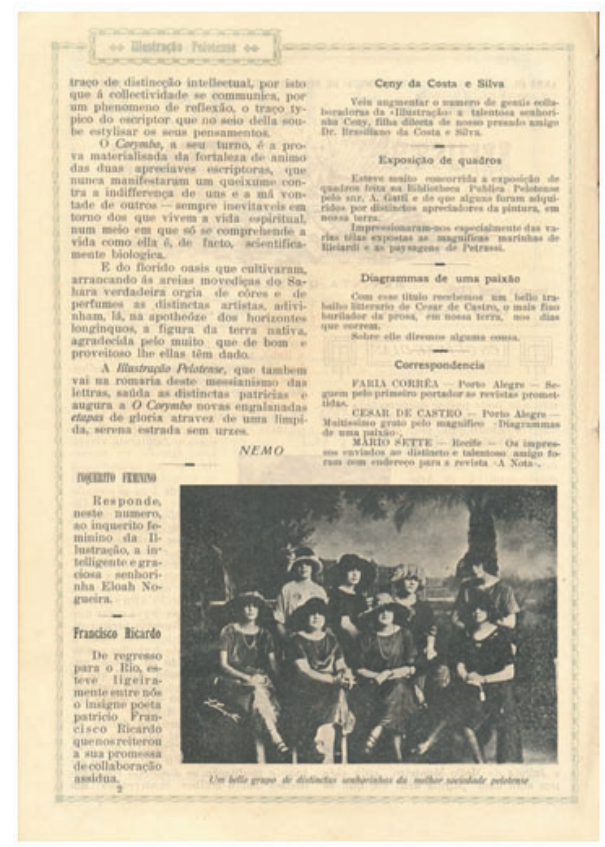

Fig. 9. Imagem da página 2 do caderno central da revista Illustração Pelotense, de $1^{\circ}$ de novembro de 1921 (ano III). A fotografia é em estilo carte de visite. Deixar-se fotografar por um profissional famoso no ramo demonstrava status social na época.

Na outra imagem (fig.10), a austeridade. Homens com terno e gravata e mulheres discretamente vestidas. Na relação entre essas duas figuras (fig.9 e 10), uma oposição entre tradição e modernidade. A primeira mostra as mudanças assimiladas pela mulher na Belle Époque da cidade, figurativizadas na forma de vestir e pelo que parece-ser independência, pois se trata de um grupo constituído só por mulheres. A outra retrata a tradição, a não-ousadia, proporcionada pela não-mudança, figurativizada pela família em trajes e postura formais. Era a afirmação do status-quo. Fora esses dois aspectos, ambas regem-se por um regime de visibilidade do querer-ser-visto, do colocar-se em cena, perpetuando suas imagens. 


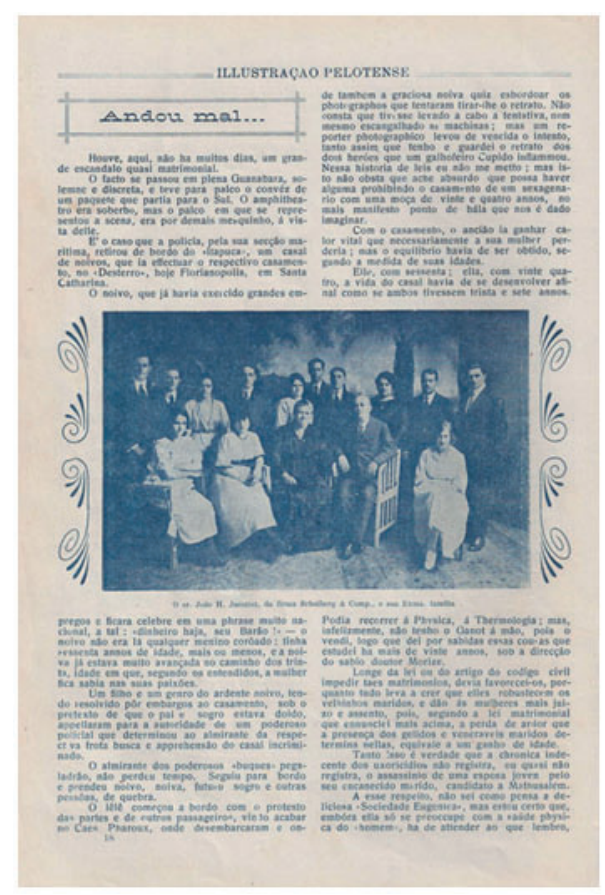

Fig. 10. Imagem da página 18 do caderno central da revista Illustração Pelotense, de 16 de janeiro de 1921 (ano III). O cenário, com coqueiros, é o mesmo encontrado em várias fotografias que aparecem na revista.

Como se fossem obras de arte, muitas carte de visite traziam a assinatura dos fotógrafos, profissionais considerados, na época, grandes artistas, verdadeiros pintores. De acordo com Oliveira (1995, p.116), “[...] a assinatura do pintor é um dos seus modos de presença na tela", uma atualização do fazer enunciativo, visto que só assina a fotografia ao finalizar o trabalho. Na fotografia das mulheres, é possível identificar o nome do fotógrafo Luiz Lanzetta, que também era o diretor artístico da revista.

O modo de vida retratado pela Illustração Pelotense estava profundamente vinculado à moda ditada na Europa, principalmente na França e, também, no centro do país. O uso de estrangeirismos era frequente e a conservação desse estilo verificou-se por todos os anos da revista. Como se viu, muitos anúncios tinham como temática o luxo e a ostentação, logo, a assimilação dos valores europeus referidos ia além da vestimenta. Modos de ser e de se comportar também são recuperados a partir da análise.

$\mathrm{Na}$ incorporação de elementos novos à cultura local, os pelotenses queriam ser como o outro, renunciando valores ultrapassados, obtusos e, desta forma, assimilando a noção de civilização à de progresso, em um discurso de modernidade, próprio da Belle Époque.

Considerando o discurso do progresso, da modernidade como moda, num sentido de apreensão da mudança mais abstrata, concorda-se com Landowski (2002, p. 123) 
quando acrescenta: "[...] a moda faz mudar os próprios sujeitos, pois, na medida em que a seguimos, adotamos novos pontos de vista sobre os objetos e sobre as coisas e, finalmente, sobre nós mesmos", embora, ainda de acordo com o autor, essas duas possibilidades da mudança se impliquem. Dos desejos individuais, privados, à consagração pública, a assimilação do "outro" foi incorporada à cidade.

Ana Claudia de Oliveira é professora doutora do PPG Comunicação e Semiótica da PUC-SP.

anaclaudiamei@hotmail.com

Fabiane Villela Marroni é professora do Programa de PósGraduação em Letras da Universidade Católica de Pelotas - PPGL/UCPel e doutora em Comunicação e Semiótica pela PUC-SP.

fvmar@terra.com.br

\section{Referências}

BUITONI, Dulcilia Schroeder. Revistas femininas: ainda somos as mesmas, como nossas mães. In: Revista Communicare - Dossiê Feminismo, São Paulo, v.14, n.1, 2014, pp. 36-44.

CIACO, João Batista Simon. Modos de presença do novo na comunicação automobilística: regimes de interação, regimes de sentido. 2010. 351p. Tese de doutorado. Programa de Pós-Graduação em Comunicação e Semiótica, Pontifícia Universidade Católica de São Paulo, São Paulo, 2010.

GONTIJO, Silvana. O mundo em comunicação. Rio de Janeiro: Aeroplano, 2001. 300p.

GREIMAS, Algirdas Julien. Semiótica figurativa e semiótica plástica. In: Significação: Revista Brasileira de Semiótica, São Paulo, n. 4, jul. 1984, pp. 18-46.

LANDOWSKI, Eric. Flagrantes delitos e retratos. In: Galáxia. 8, 2004, pp. 31-70.

Presenças do outro. São Paulo: Editora Perspectiva, 2002. 215p. (Coleção Estudos, n.183).

A sociedade refletida. Ensaios de sociossemiótica. Tradução de Eduardo Brandão. São Paulo: EDUC/Pontes, 1992. 213p. (Tradução do Original La société réfléchie).

MAGALHÃES, Mario Osorio. Opulência e cultura na Província de São Pedro do Rio Grande do Sul: um estudo sobre a história de Pelotas (1860-1890). $2^{\text {a }}$ ed. Pelotas: Editora da Universidade Federal de Pelotas; Coedição Livraria Mundial, 1993. 312p.

NEEDELL, Jeffrey D. Belle Époque Tropical. Sociedade e cultura de elite no Rio de Janeiro na virada do século. Tradução de Celso Nogueira. São Paulo: Companhia das Letras, 1993. 383p. (Tradução do Original A tropical Belle Époque: elite culture and society in turn-of-the-century Rio de Janeiro).

OLIVEIRA, Ana Claudia de. Espaços-tempos (pós)modernos ou na moda, os modos. In: GUINSBURG, J.; BARBOSA, A. M. O pós-modernismo. São Paulo: Perspectiva, 2005. p. 473-531. 
Expressionismo como modo de vida e moda. In: GUINSBURG, J. O expressionismo. São Paulo: Perspectiva, 2002. pp. 543-605.

. As Semioses pictóricas. In: Face. Revista semestral de Semiótica e Comunicação, São Paulo, v. 4, n. 2, pp. 104-145, jul./dez.1995.

SANTOS, Carlos Alberto Avila. Espelhos, máscaras, vitrines: estudo iconológico de fachadas arquitetônicas: Pelotas, 1870-1930. Pelotas: EDUCAT- Editora da Universidade Católica de Pelotas, 2002. 143p.

\section{Revista Illustração Pelotense}

1919

Illustração Pelotense. Anno I, Número 1. Pelotas. 20p.

Illustração Pelotense. Anno I, Número 4. Pelotas, 1 de setembro de 1919. 20p.

1921

Illustração Pelotense. Anno III, Número 10. Pelotas, 16 de janeiro de 1921.

Illustração Pelotense. Anno III, Número 12. Pelotas, 16 de junho de 1921. 28p.

Illustração Pelotense. Anno III, Número 21. Pelotas, 1 de novembro de 1921. 28p.

1923

Illustração Pelotense. Anno V, Número 19 e 20. Pelotas, 1 de novembro de 1923. 20p.

1924

Illustração Pelotense. Anno VI, Número 18. Pelotas, 1 de novembro de 1924. 20p.

Illustração Pelotense. Anno VI, Número 21. Pelotas, 16 de dezembro de 1924. 20p.

1925

Illustração Pelotense. Anno VII, Número 15. Pelotas, 1 de agosto de 1925. 20p.

Illustração Pelotense. Anno VII, Número 16. Pelotas, 16 de agosto de 1925. 20p.

Illustração Pelotense. Anno VII, Número 17 e 18. Pelotas, 7 de setembro de 1925. 20p. 